\begin{tabular}{ll}
\hline \hline MINING AND METALLURGY INSTITUTE BOR & ISSN: 2334-8836 (Štampano izdanje) \\
UDK: 622 & ISSN: 2406-1395 (Online) \\
\hline \hline
\end{tabular}

\title{
IMPACT OF DRILLING IN THE OPEN PIT MINING ON THE ENVIRONMENT ${ }^{* *}$
}

\begin{abstract}
In order to provide better and easier loading of useful component and overburden, the drilling and blasting belong to the important work operations at the open pits. Borehole drilling represents a source of harmful respirable mineral dust beside the applied measures for its prevention at the place of creation. Dust emissions during borehole drilling depends on a method and speed of drilling, borehole diameter, mechanical rock properties and applied method to capture dust in order to suppress the dust concentration in the working and living environment of the open pit.

Keywords: drilling, dust, environment
\end{abstract}

\section{INTRODUCTION}

Air is a very important part for the existence of human and other living orga-nisms. The main sources of air pollution can be broadly categorized in natural as well as in anthropogenic emissions (Tofan Kumar Rout et al., 2014). Natural emissions are not yet under human control, with the air pollution control technologies being implemented to suppress the human emissions (Tofan Kumar Rout et al., 2014). The main anthropogenic sources of the air pollution are industry (thermal power plants, refineries, open pits, etc.), traffic and home (domestic) emissions. Between these various sources of the air pollution, mining is the main source of dust pollution (Ghose and Majee, 2000).

The coal open pits use a large-scale mechanization and in their work a large amount of dust and gases is realized, which negatively affect the human health (Dhar, 1994). Various mining processes that release a large amount of dust, especially at the open pits, are: removal of overburden, removal of waste, mining and drilling operations, coal mining, transport of useful components or waste on transport routes, operating of crushing plants, etc. The rate of dust drop and its chemical composition are needed in quantitative and qualitative frameworks to the dust pollution in a particular region. Managing dust from the mine is important because it can affect local and regional air quality and negatively affects the local community and present a risk to public health (Pandey et al., 2008).

\section{DRILLING}

Drilling of boreholes in a useful component or accompanying rocks represents the main and permanent source of very stable and highly dispersed systems of floating,

\footnotetext{
* Mining and Metallurgy Institute Bor

** This work is the result of the Project No. TR33021 "Research and Monitoring the Changes of the Stress Strain State in the Rock Mass "In-Situ" around the Underground Rooms with Development of Models with Special Reference to the Tunnel of the Krivelj River and Pit Bor", funded by the Ministry of Education, Science and Technological Development of the Republic of Serbia
} 
respirable, mineral dust (M. Miljković, 1998).

The empirical formula (S.F. Sepelen, G.A. Radcenko) for determining the dust emission in drilling of boreholes is presented in the form:

$$
E=i V_{o} d_{o}^{2} \rho f K_{1} K_{2} K_{3},(\mathrm{mg} / \mathrm{s})
$$

where:

- E - dust emission in drilling, mg/s

- $\mathrm{i}$ - coefficient taking the drilling and cleaning method of the borehole $(\mathrm{i}=$ $155 \cdot 10^{-8}$ in normal drilling and borehole washing with water, $\mathrm{i}=90 \cdot 10^{-8}$ when the water softeners are added, $\mathrm{i}=16 \cdot 10^{-8}$ at optional drilling and borehole washing with water),

- $\mathrm{V}_{\mathrm{o}}$ - drilling speed, $\mathrm{mm} / \mathrm{s}$,

- $\mathrm{d}_{\mathrm{o}}$ - diameter of borehole, $\mathrm{mm}$,

- $\mathrm{r}$ - rock density,

- f - strength coefficient according to Protodjakon,

- $\mathrm{K}_{1}$ - coefficient of simultaneous operation for multiple drilling hammers $\left(\mathrm{K}_{1}=1\right.$ for one drilling hammer, $\mathrm{K}_{1}=1.7$ for two drill hammers, $K_{1}=2.7$ for three drilling hammers, for drillers in the open pit exploitation $\mathrm{K}_{1}=1$ ),

- $\mathrm{K}_{2}$ is the coefficient of inclination angle of borehole $\left(\mathrm{K}_{2}=1\right.$ for horizontal, $\mathrm{K}_{2}=1.3$ for inclined and vertical upwards, $\mathrm{K}_{2}=0.7$ for inclined and vertical downwards),

- $\mathrm{K}_{3}$ - coefficient taking into account the impact of the type of hammer drill or drill $\left(\mathrm{K}_{3}=1.3\right.$ for working with manual drilling hammer, $\mathrm{K}_{3}=1$ for drilling hammer or chisel on rack, $\mathrm{K}_{3}=0.5$ for pivot drill hammer or hydraulic pushing drilling accessories).

Drilling of boreholes for the primary massive blasting at pits open is carried out most often by drilling rigs which can drill boreholes $200-300 \mathrm{~mm}$ in diameter and depths up to $20-30 \mathrm{~m}$.

Having in mind the use of this type of equipment, where the boreholes of large diameter are drilled, as a result, a large amount of dust is created that endangers the working and living environment in the area of the surface mine. For this reason, the manufacturers of drilling rigs install the special systems - devices for suppressing the formation of dust by means of water or decking devices, hermetization of the mouth of boreholes and dust aspiration of from the borehole and capture of dust, using the dry cyclones or sleeves and other dust filters for dust capture by the airborne air. The purified air is evacuated into the atmosphere through a pipe.

The drilling rig is a point source of dust, and the emission of dust depends on the efficiency of filter for cleaning the exhaust air, that is, the concentration of dust in the air of the outlet pipe and its quantity:

$\mathrm{E}=\mathrm{Q}_{\mathrm{v}}\left(\mathrm{N}_{\mathrm{izl}}-\mathrm{N}_{\mathrm{p}}\right), \mathrm{mg} / \mathrm{s}$

where:

- Q - capacity of the air aspiration device, $\mathrm{m}^{3} / \mathrm{s}$,

- $\mathrm{N}_{\mathrm{izl}}-\mathrm{N}_{\mathrm{p}}$ - dust concentration on the outlet pipe and in the outer air, $\mathrm{mg} / \mathrm{m}^{3}$.

\section{DUST CONTROL}

The dust control created by the air compressor during drilling is necessarily an evil.

There are two systems for the acceptance and suppression of dust:

1. Dry dust collection system

2. Dust water suppression (wet method)

For dust control, the area surrounding the hole is closed by so called hood dust. "Hoods for dust" are closed by the side with curtains. The dust control system on the drill must be used in combination with dust hood and curtain. The two most common types of dust control are dry dust collectors (dry method), and water injection (wet method). Dust collectors are essentially large vacuum cleaners that pull - take dust from the dust hood and lead it through a system of elemental filters. Water injection system injects water in the form of fog in the air current. This system represents a more efficient solution for providing a minimum amount of 
dust, but the introduction of water into the borehole may slow down the drilling process by increasing the cutting density (broken material at drilling) at the bottom of the hole, which compressed air should start and lift. Also, such a system requires a constant water supply, that is, frequent replenishment of the water reservoir, and in winter conditions, the worn-out developed heating systems must be used.

\subsection{Dust suppression systems, cleaning of sucked air and dust emission}

Within the drill rig, there is a dust suppression system, cleaning the sucked air.

Dry drilling is done without the use of water for dust control. Dust control is achieved by a dust extraction system mounted on a drill. These systems have the ability to function in different climatic conditions, that is, they are not susceptible to freezing at lower temperatures, unlike the water systems, and can be up to 99 percent effective if properly are maintained. There are different types of dry dust collection systems that are used depending on the drill size. Medium to large diameter drills have a system shown in Figure 1.

Dust is generated by the outlet air from the borehole, which in fact represents the compressed air that is inserted through a drill rod and comes out through the crown, and has the role of cleaning and ejecting the sections through the borehole. In a system with adequate function, these sections are collected in the aspiration chamber and on a deposited heap of fine material around the mouth of borehole. This dust, obtained by drilling, located in a chamber, is removed by a dust collector system. This system (dust collector) consists of the exhaust fans and filters that purify air from the chamber. This is mainly a self-cleaning system, in which the compressed air is used which pulses through the filters at certain time intervals to clean them and prevent blockage. The fine-filtered fine material then falls through the bottom of collector to the dust dump.

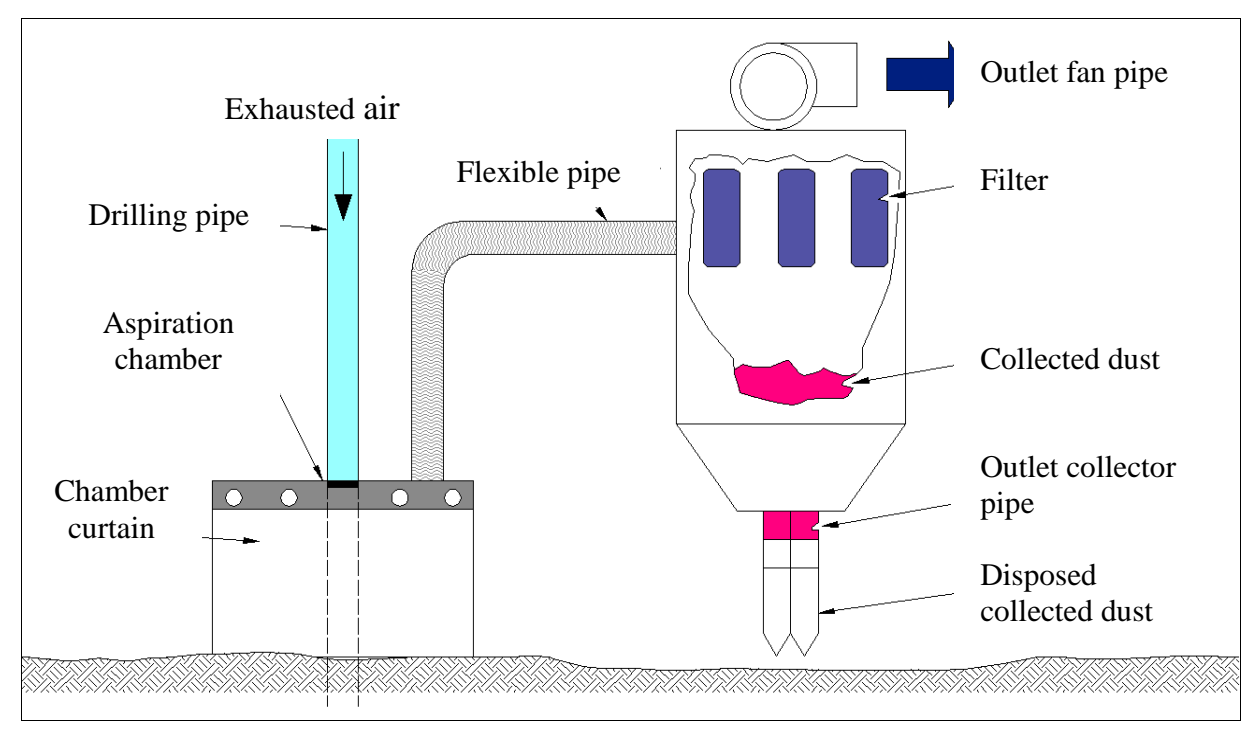

Figure 1 Dry system for dust collecting

Drills with a smaller diameter of drilling have the system shown in Figure 2. Sche matic shows the operation of this type of system. The difference in a system with a 
larger diameter drill is that this system collects the all materials in the cutting-drilling, then sends it to a large separation cyclone located on a drill bit to remove the large diameter (large granulation) cuts and then sends the residue to the dust collector on the back of drill, where dust and fine cuts are released (small granulation material).
Maintenance a dust collection system is important for maintenance the effective dust control on these systems. The two most important things in maintenance are: the filters should be replaced before they become clogged, and the dust release can be significant if drilling rods and crowns are not properly maintained.

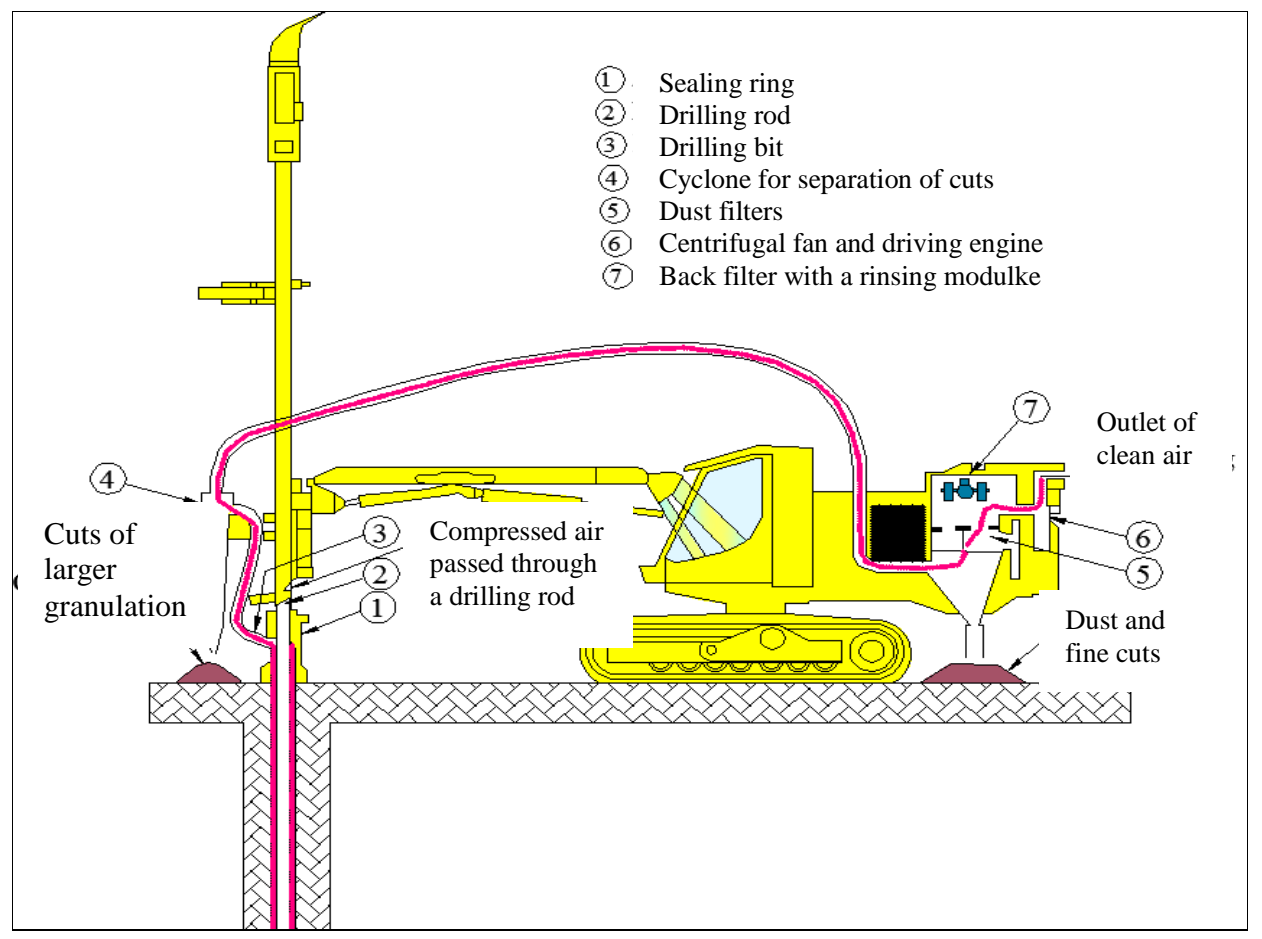

Figure 2 Dry system for dust collecting in drills with smaller drilling diameter

The system for dust suppression with water (wet method) is shown in Figure 3.

The best method for dust control in drilling at the open pits is to use the wet drilling techniques. Wet drilling injects water together with air to wash the cuts from the borehole as shown in Figure 3. Testing has shown that this technique can provide dust control with an efficiency of up to 96 percent [USBM 1987]. Water injection requires monitoring by the operator for effective dust control. The required amount of water for dust control is not great. Typical water flow in wet drilling systems is generally in the range of 0.37 to $7.5 \mathrm{l} / \mathrm{min}$, but this va-ries depending on the type of drill, geology, and the humidity level of drilling material. Too little water leads to a reduction the efficiency of dust control while too much water leads to the operational problems with the drill. It is concluded that the amount of water required for dust control depends on the type of drill and drilling material. 


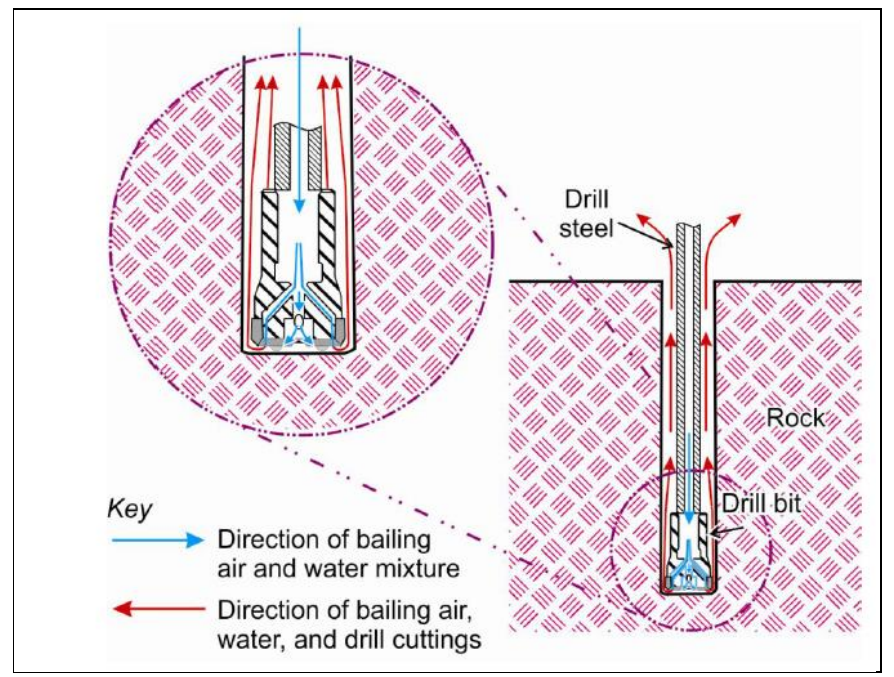

Figure 3 Wet drilling method

\section{EFFICIENCY OF THE WET \\ METHOD AND DUST \\ ELIMINATION DURING \\ DRILLING AT THE OPEN PITS}

In order to reduce dust when drilling on a drill rig, it is mandatory that the dust extraction and purification device of the suctionned dust air is in the proper state. A rubber seal should be installed on the borehole open for dust suction, which, after filtering the purified air, is released into atmosphere with a concentration less than $50 \mathrm{mg} / \mathrm{m}^{3}$.

During the borehole drilling, dust may fall into the environment if the dusting system is not in a function. Borehole drilling rigs have the installed devices for cleaning the boreholes from fragments by compressed air through which the water is added by the injector.

The scattered water in the form of fog and fine droplets with dust from the borehole creates agglomerates that compressed air takes and deposits under a hood with which the borehole is isolated from the environment. The reduction efficiency is reduced by reduction the amount of water, and completely is absent if the boreholes are cleaned only by compressed air (dry drilling).

The efficiency $\left(\eta_{\mathrm{i}}\right)$ of dust wetting with water added to the compressed air is $60 \%$ $\left(\eta_{\mathrm{i}}=0.6\right)$.

At the drilling machine beside the wet process, an additional air cleaning method of dust of less than $10 \mu \mathrm{m}$ diameter is applied. The efficiency of controlling the dust emission of less than $10 \mu \mathrm{m}$ diameter is about $80 \%$ if the device for dust aspiration is in the correct state.

The efficiency coefficient of aspiration and cleaning of air on drilling in the proper operation of device is:

$$
\eta_{i}=\left[1-\left(1-\mu_{1}\right)\left(1-\mu_{2}\right)\right]=0,92
$$

Dust reduction effect is:

$$
N=\frac{1}{\left(1-\mu_{1}\right)\left(1-\mu_{2}\right)}=12,5 \text { times }
$$

where:

$\mu_{1}$ and $\mu_{2}$ - coefficients 


\section{CONCLUSION}

Drilling as a technological phase of exploitation the mineral raw materials at the open pits causes the formation of large quantities and concentration of dust. Such a negative effect on the working and living environment should be controlled by the efficient dust suppression and dust cleaning systems. As the efficiency of these systems is shown as over $90 \%$, and more importan-tly, the total dust concentrations generated by drilling can be reduced by 12.5 times.

\section{REFERENCES}

[1] Tofan Kumar Rout, Reginald Ebhin Masto, Pratap Kumar Padhy, Joshy George, Lal Chand Ram, Sudip Maity. Dust Fall and Elemental Flux in a Coal Mining Area. Journal of Geochemical Exploration, 144 (2014), 443-455.

[2] Ghose M. K., Majee S. R., Assessment of Dust Generation due to Opencast Coal Mining-an Indian Case Study. Environ. Monit. Assess. 2000, 67, 255256.

[3] Dhar B. B., 1994. Changing Environment Scenario in Mining Industry. J. Mines Met. Fuel 309-314.

[4] Pandey S.K., Tripathi B.D., Mishra V. K., 2008. Dust deposition in a subtropical opencast coalmine area, India. J. Environ. Manag. 86, 132-138.

[5] M. Miljković, Z. Stojković, The Effect of Open Pit Metal Ore Mining on Ecological Factors of the Environment, Monograph, Bor 1998. (in Serbian)

[6] USBM [1987]. Optimizing Dust Control on Surface Coal Mine Drills. By Page SJ. U.S. Department of the Interior, Bureau of Mines Technology News 286.

[7] T. Apostolovski Trujić, M. Mikić, V. Tasić, Air Quality Control in the Area of Environmental Influence, $46^{\text {th }}$ International October Conference on Mining and Metallurgy-Proceedings, Serbia, 2014, 545-549.

[8] M. Mikić, D. Kržanović, R. Rajković. Effect of Exploitation at Social
Community, and Other Public Facilities in Zone of Open Pit Južni Revir in Majdanpek, Mining 2012, Privredna Komora Srbije, 397-402 (in Serbian)

[9] M. Mikić, R. Rajković, D. Kržanović. Recultivation of Degraded Area at the Open Pit Južni Revir in Majdanpek, Mining 2012, Privredna Komora Srbije, 491-499 (in Serbian)

[10] R. Rajković, M. Bugarin, V. Marinković: Analysis the Stability of the Waste Dump "Oštreljski planir" of the Open Pit "Bor" in a Function of Watering, Mining and Metallurgy Engineering Bor, 3/2013, pp. 57-64 (in Serbian)

[11] M. Ignjatović, S. Ignjatović, M. Negovanović, R. Rajković, L. Djurdjevac Ignjatović, D. Ignjatović: Determination of the Final Slope Angle of the Open Pit Mine During Exploitation of Oil Shale from Aleksinac Deposit During GeoStudio2007 - SLOPE/W program; TTEM - Technics Technologies Education Management 2011/3; pp. $615-621$.

[12] M. Ignjatović, R. Rajković, B. Rajković, D. Milanović, M. Popović: Stability Analysis of the Open Pit "Progorelica" by the Bishop Method and Program Plan Failure Analysis; II International Symposium "Mining 2011" Mining Presents State and Future Prospects and Sustainable Development; Vrnjačka banja 10 - 13 May 2011; pp. $599-603$.

[13] R. Lekovski, M. Mikić, D. Kržanović; The Impact of the Flotation Tailing Dumps on the Environment of Bor and Protection Measures, Mining and Metallurgy Engineering Bor, 2/2013, pp. 107-116 (in Serbian)

[14] M. Mikić, D. Kržanović, M. Jovanović, M. Maksimović: Review of the Open Mine South Mining District Majdanpek Impact on the Environment and Protective Measures, Mining and Metallurgy Engineering Bor 3/2015, pp.1-16 (in Serbian) 